\title{
Performance Evaluation of OMDV and DSDV Routing Protocols with Video Streaming on the Wireless Mesh Network
}

\author{
https://doi.org/10.3991/ijim.v14i20.13733
}

Siti Ummi Masruroh

Universitas Islam Negeri Syarif Hidayatullah Jakarta, Jakarta, Indonesia

\author{
Ahmad Nurul Fajar ${ }^{(凶)}$ \\ Bina Nusantara University, Jakarta, Indonesia \\ afajar@binus.edu
}

Mufid Fajar Alghifari, Luh Kesuma Wardhani

Universitas Islam Negeri Syarif Hidayatullah Jakarta, Jakarta, Indonesia

\begin{abstract}
Video Streaming is a method to deliver multimedia content that allows files to be used or watched directly without the need to download and save it. Video streaming also includes image processing, in image processing, there is a component to compare the value of an image, which is PSNR. This paper will compare the reactive and proactive routing protocol performance of AOMDV and DSDV using parameters of PSNR, Packet loss, and Throughput in Wireless Mesh Network (WMN) for video streaming. The simulation uses 4, $16,36,64$, and 100 nodes. The results of the paper are the AOMDV routing protocol with the greater variation in the number of nodes and the distance between nodes resulting in higher packet loss, decreasing throughput, and decreasing values of PSNR. While in DSDV routing protocol with the greater variation in the number of nodes and distance between nodes has an impact on the increase of packet loss value, a very drastic decrease throughput value, a decrease in PSNR value and some scenarios does not produce PSNR values. The comparison of PSNR values between the two routing protocols is also influenced by variations in the number of nodes and distances between nodes along with packet loss and throughput parameters. The greater packet loss will decrease the PSNR value generated.
\end{abstract}

Keywords-AOMDV, DSDV, Node distance, Packet loss, Throughput, Variation of nodes number, PSNR, Wireless Mesh Network

\section{Introduction}

Wireless Sensor Networks (WSNs) are composed of a great huge number of nodes, which has significant research value and already successful applied in various fields, such as environmental monitoring, military applications, and target tracking etc (Han 
et al., 2020). Wireless Mesh Network (WMN) is a type of wireless broadband access technology based on the IP protocol. WMNs are emerging as the more lucrative technology for determining wideband connectivity (Miloud Ar-Reyouchi et al., 2020). WMN can profit from WLAN and Ad hoc. Mode of connecting multipoint to multipoint communication, with automatic networking, automatic repair, hop uplink, and self-management nodes.

The rapid growth of network protocols and wireless communications, such as 802.11 and cellular networks, brings additional access to multimedia streaming services such as online movies, television news, music videos, etc. Video streaming is a method of delivering multimedia content that allows files to be used or watched directly without the need to download and save the data.

Video streaming also includes image processing. In image processing, there is a component to compare the value of a video, PSNR. MSE (Mean Square Error) and PSNR (Peak Signal to Noise Ratio) where both of these values are inversely proportional. For the best value, we are based on the highest PSNR value. The higher the PSNR value, the higher the quality of video images (Zhu et al., 2018).

To generate the value of PSNR, there are 2 types of routing protocols are used, reactive, and proactive. Reactive protocol (or on-demand) routing protocols find the necessary routes, build and maintain routes. Proactive protocols utilize periodic control message exchanges between routers ensuring that routes to each host are always known.

Streaming video quality is affected by the choice of a routing protocol. In previous research conducted by Sabrina Nefti and Maamar Sedrati in 2016 entitled "PSNR and Jitter Analysis of Routing Protocols for MANET Networks Video Streaming in Sparse, using NS2 and the Evalvid Framework" carried out the combined effects of sparse and density on the PSNR and jitter performance of two MANET routing protocols, namely AODV (reactive) and DSDV (proactive) for video streaming applications. The study resulted in the AODV routing protocol providing high PSNR results over a period faster than DSDV because it was influenced by sparse and density

Based on previous research, this study will compare the reactive and proactive routing protocol performance of AOMDV and DSDV using the PSNR, Packet loss, and Throughput parameters in the Wireless Mesh Network (WMN). Therefore, this research will be compiled as a thesis with the title "Evaluation of the Performance of AOMDV and DSDV Routing Protocols with Streaming Video on the Wireless Mesh Network".

\section{$2 \quad$ Related Works}

The first paper proposed by Sabrina, et al (2016) entitled PSNR and Jitter Analysis of Routing Protocols for Video Streaming in Sparse MANET Networks, using NS2 and the Evalvid Framework (Nefti \& Sedrati, 2016). In this study using jitter as a parameter, AODV as a routing protocol, and MANET as a topology but only using two parameters. Therefore, in this study using two different parameters packet loss and throughput, and adding a variety of nodes. The second paper proposed by Munta- 
sir Jaber (2017) with the title A Simulation of a Networked Video Monitoring System Using NS2 uses the average delay parameter but only uses one scenario (Al-Asfoor, 2017). Therefore, in our paper using two scenarios with variations in the number of nodes and the distance between nodes, adding packet loss parameters. The third paper proposed by R. Raja Sekhar, et al (2016) with the title An Efficient Multipath Routing Protocol with Replication for On-demand Video Streaming in MANETs using pause time parameters, MANET, and AODV routing protocol but only use one scenario (Sekhar \& Chennareddy, 2016). Therefore, in our paper using two scenarios with variations in the number of nodes and the distance between nodes. The fourth paper proposed by Younis, et al (2017) with the title Video Quality Evaluation of MPEG-4 Using (MOS) Mean Opinion Score in NS-2 Using three variations of packet size but using only one parameter (Wani et al., 2017). Therefore, in our paper using two scenarios with variations in the number of nodes and the distance between nodes, adding packet loss parameters. The fifth paper proposed by Weiwei Zhang, et al (2017) with the title AODV Routing Analysis of Protocol in Wireless Mesh Network Using packet transmission delay parameters but only uses one scenario with one variation of nodes and areas (Zhang et al., 2017). Therefore, in our paper using two scenarios with variations in the number of nodes and the distance between nodes, adding parameters packet loss, throughput, and PSNR.

\section{$3 \quad$ Research Method}

The method used in this paper is a simulation method. The method starts with literature studies, similar research studies, identification of problems in which data collection comes from the website of the video streaming provider.

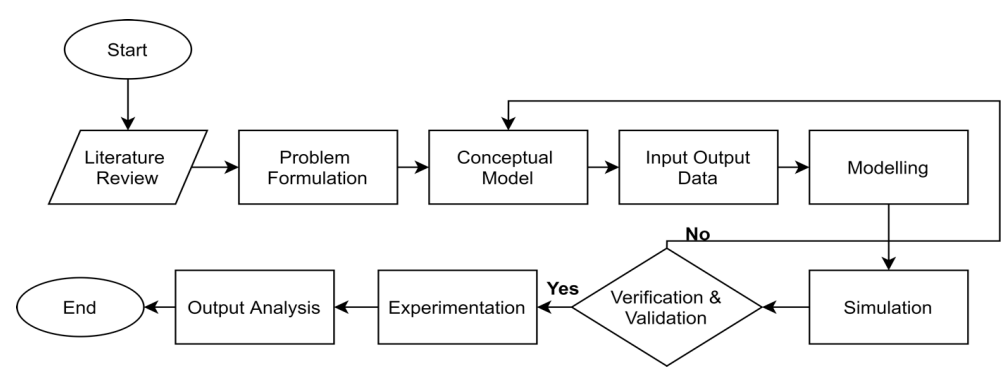

Fig. 1. Simulation method (Madani et al., 2012)

This simulation method consists of several stages, including:

1. Problem formulation, analyzes the routing protocol performance of AOMDV and DSDV on variations in the number of nodes and distance between nodes based on packet loss, throughput, and PSNR parameters.

2. Conceptual model, the design and description of the concept model for the simulation will be carried out. At this stage, the author uses NS2 software. 
3. Input/output data, Input is in the form of attributes needed in the simulation, namely nodes, distances between nodes, and so on. And output based on formulated problems, namely packet loss, throughput, and PSNR.

4. Modeling, Determine the parameters that will be used during the simulation, at this stage scenarios will be used to be used for simulation as in table.

5. Simulation, the implementation of the model is carried out, which is to enter predetermined parameters and implement the scenario following the plans that have been made.

Table 1. Simulation Structure

\begin{tabular}{|l|c|}
\hline \multicolumn{1}{|c|}{ Parameter } & Values \\
\hline MAC & 802.11 \\
\hline Distance Between Nodes $(\mathrm{m})$ & $20,50,100$, dan 150 \\
\hline Number of Node & $2^{2}, 4^{2}, 6^{2}, 8^{2}$ dan $10^{2}$ \\
\hline Simulation Time & $66 \mathrm{~s}$ \\
\hline Routing Protocol & AOMDV \\
\hline Traffic Type & CBR \\
\hline Transmission Protocol & UDP \\
\hline Application & Video Streaming \\
\hline
\end{tabular}

6. Verification and validation, At this stage verification and validation of the previous stages are carried out, so that the simulation is ready to be carried out.

7. Experimentation, the NS2 software carries out a simulation process following what was made in the previous stage.

8. Output Evaluation, The output will be used as the performance criteria of AOMDV and DSDV routing protocol on variations in the number of nodes and distance between nodes consisting of packet loss, throughput, and PSNR.

\section{Result}

A comparison of packet loss, throughput, and PSNR from the AOMDV and DSDV routing protocol using the number of nodes $4,16,36,64$, and 100 with internode distances of $20 \mathrm{~m}, 50 \mathrm{~m}, 100 \mathrm{~m}, 150 \mathrm{~m}$. 
Table 2. Comparison of packet loss AOMDV and DSDV (A: AOMDV, D: DSDV, Dist: Distance)

\begin{tabular}{|c|c|c|c|c|c|c|}
\hline \multicolumn{2}{|c|}{ Packetloss (\%) } \\
\hline \multirow{2}{*}{ Dist (m) } & \multirow{2}{*}{$\boldsymbol{R P}$} & \multicolumn{7}{c|}{ Node } \\
\cline { 2 - 7 } & & $\mathbf{4}$ & $\mathbf{1 6}$ & $\mathbf{3 6}$ & $\mathbf{6 4}$ & $\mathbf{1 0 0}$ \\
\hline \multirow{3}{*}{20} & $\mathrm{~A}$ & 0 & 0 & 0 & 0 & 0 \\
\cline { 2 - 7 } & $\mathrm{D}$ & 1,2 & 1,3 & 2 & 3 & 19,9 \\
\hline \multirow{2}{*}{50} & A & 0 & 0 & 0 & 0 & 0 \\
\cline { 2 - 7 } & D & 1,2 & 1,3 & 20,8 & 20,7 & 39,9 \\
\hline \multirow{2}{*}{100} & A & 0 & 0 & 0,9 & 1,3 & 2,4 \\
\cline { 2 - 7 } & D & 1,2 & 21,4 & 72,5 & 100 & 100 \\
\hline \multirow{2}{*}{150} & A & 0 & 0 & 1,9 & 9,4 & 10,19 \\
\cline { 2 - 7 } & D & 1,2 & 55,1 & 100 & 100 & 100 \\
\hline
\end{tabular}

In table 2, the results of the comparison of packet loss are explained using AOMDV and DSDV routing protocol based on the number of nodes and the distance between nodes.

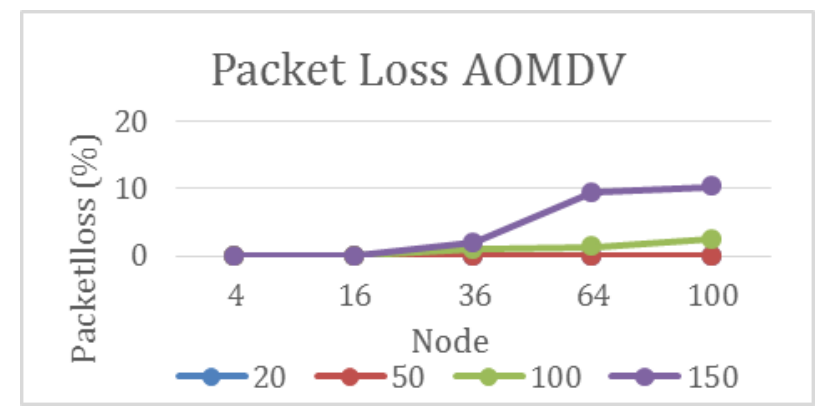

Fig. 2. Packet loss AOMDV chart

In Figure 2 shows a comparison of packetloss values in the AOMDV routing protocol with node variations and variations in distance between nodes. At node 100 and a distance of $150 \mathrm{~m}$ packet reaches the greatest value.

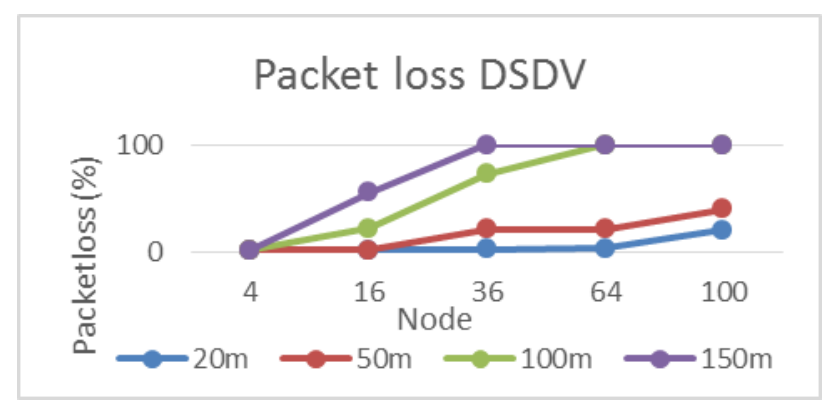

Fig. 3. Packet loss DSDV chart 
Figure 3 shows a comparison of packet loss values in DSDV routing protocol with node variations and variations in distance between nodes. There are 5 results that have the largest packet loss value, namely nodes 64 and 100 at a distance of $100 \mathrm{~m}$ and nodes 36,64 , and 100 at a distance of $150 \mathrm{~m}$ with a packet loss value of $100 \%$.

Table 3. Comparison Throughput AOMDV and DSDV

$$
\text { (A: AOMDV, D: DSDV, Dist: Distance) }
$$

\begin{tabular}{|c|c|c|c|c|c|c|}
\hline \multicolumn{7}{|c|}{ Throuhput (\%) } \\
\hline \multirow{2}{*}{ Dist (m) } & \multirow{2}{*}{$\boldsymbol{R P}$} & \multicolumn{7}{|c|}{ Node } & $\mathbf{1 0 0}$ \\
\cline { 3 - 7 } & & $\mathbf{4}$ & $\mathbf{1 6}$ & $\mathbf{3 6}$ & $\mathbf{6 4}$ & 80,46 \\
\hline \multirow{3}{*}{20} & A & 80,46 & 80,46 & 80,46 & 80,46 & 64,03 \\
\cline { 2 - 7 } & D & 77,42 & 77,35 & 76,97 & 76,16 & 80,45 \\
\hline \multirow{2}{*}{50} & A & 80,46 & 80,46 & 80,46 & 80,45 & 49,5 \\
\cline { 2 - 7 } & D & 77,42 & 77,35 & 63,24 & 63,26 & 77,7 \\
\hline \multirow{2}{*}{100} & A & 80,46 & 80,46 & 79 & 79,1 & 0 \\
\cline { 2 - 7 } & D & 77,42 & 62,68 & 21,82 & 0 & 71,44 \\
\hline \multirow{2}{*}{150} & A & 80,46 & 80,44 & 78,98 & 71,12 & 0 \\
\cline { 2 - 7 } & D & 77,42 & 35,48 & 0 & 0 & 0 \\
\hline
\end{tabular}

In table 3 the results of a comparison of throughput using AOMDV and DSDV routing protocol are based on the number of nodes and the distance between nodes.

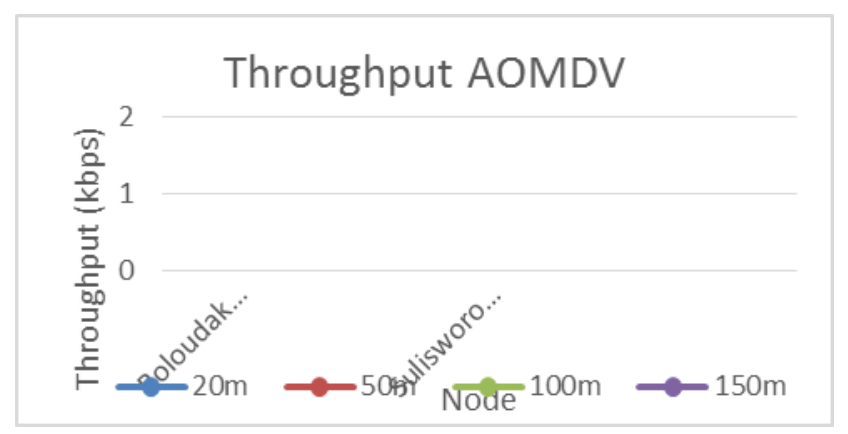

Fig. 4. Throughput AOMDV chart

Figure 4 shows a comparison of the AOMDV routing protocol throughput with node variations and variations in distance between nodes. At a distance of $20 \mathrm{~m}$ and $50 \mathrm{~m}$ has the largest throughput value. 


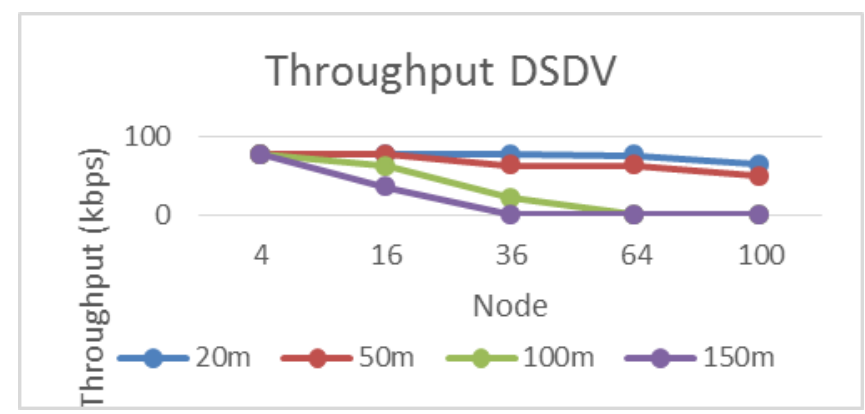

Fig. 5. Throughput DSDV chart

Figure 5 shows a comparison of the DSDV routing protocol throughput with node variations and distance variations between nodes. The simulation results show the largest throughput value occurs at node 4 at each distance between nodes. The movement of throughput on DSDV tends to decrease compared to AOMDV (Setijadi, 2018).

A large number of nodes and the amount of distance between nodes affect the performance of a routing protocol (Nefti \& Sedrati, 2016).

Table 4. Effect of number of node and distance on PSNR (A: AOMDV, D: DSDV, Y: PSNR generated, N: PSNR not generated)

\begin{tabular}{|c|c|c|c|c|c|c|c|c|}
\hline \multicolumn{9}{|c|}{ PSNR } \\
\hline \multirow{2}{*}{ Node } & \multicolumn{2}{|c|}{$20 \boldsymbol{m}$} & \multicolumn{2}{c|}{$50 \boldsymbol{m}$} & \multicolumn{2}{c|}{$\mathbf{1 0 0} \boldsymbol{m}$} & \multicolumn{2}{c|}{$\mathbf{1 5 0 m}$} \\
\cline { 2 - 10 } & $\boldsymbol{A}$ & $\boldsymbol{D}$ & $\boldsymbol{A}$ & $\boldsymbol{D}$ & $\boldsymbol{A}$ & $\boldsymbol{D}$ & $\boldsymbol{A}$ & $\boldsymbol{D}$ \\
\hline 4 & $\mathrm{Y}$ & $\mathrm{Y}$ & $\mathrm{Y}$ & $\mathrm{Y}$ & $\mathrm{Y}$ & $\mathrm{Y}$ & $\mathrm{Y}$ & $\mathrm{Y}$ \\
\hline 16 & $\mathrm{Y}$ & $\mathrm{Y}$ & $\mathrm{Y}$ & $\mathrm{Y}$ & $\mathrm{Y}$ & $\mathrm{N}$ & $\mathrm{Y}$ & $\mathrm{N}$ \\
\hline 36 & $\mathrm{Y}$ & $\mathrm{Y}$ & $\mathrm{Y}$ & $\mathrm{N}$ & $\mathrm{Y}$ & $\mathrm{N}$ & $\mathrm{Y}$ & $\mathrm{N}$ \\
\hline 64 & $\mathrm{Y}$ & $\mathrm{Y}$ & $\mathrm{Y}$ & $\mathrm{N}$ & $\mathrm{Y}$ & $\mathrm{N}$ & $\mathrm{Y}$ & $\mathrm{N}$ \\
\hline 100 & $\mathrm{Y}$ & $\mathrm{N}$ & $\mathrm{Y}$ & $\mathrm{N}$ & $\mathrm{Y}$ & $\mathrm{N}$ & $\mathrm{Y}$ & $\mathrm{N}$ \\
\hline
\end{tabular}

In table 4, it is explained on the number of nodes and the distance between nodes where PSNR can be generated based on the selection of AOMDV and DSDV routing protocols. The following is a PSNR table that can be generated.

Table 5. PSNR value at node 4 AOMDV

\begin{tabular}{|c|c|c|c|c|}
\hline \multicolumn{5}{|c|}{ Average PSNR (dB) } \\
\hline \multirow{2}{*}{ Node } & \multicolumn{4}{|c|}{ Distance (m) } \\
\cline { 2 - 5 } & $\mathbf{2 0}$ & $\mathbf{5 0}$ & $\mathbf{1 0 0}$ & $\mathbf{1 5 0}$ \\
\hline 4 & 28.767 & 28.767 & 28.767 & 28.767 \\
\hline
\end{tabular}


Table 6. PSNR value at node 4 DSDV

\begin{tabular}{|c|c|c|c|c|}
\hline \multicolumn{5}{|c|}{ Average PSNR (dB) } \\
\hline \multirow{2}{*}{ Node } & \multicolumn{4}{|c|}{ Distance (m) } \\
\cline { 2 - 5 } & $\mathbf{2 0}$ & $\mathbf{5 0}$ & $\mathbf{1 0 0}$ & $\mathbf{1 5 0}$ \\
\hline 4 & 29.864 & 28.240 & 28.240 & 28.240 \\
\hline
\end{tabular}

Based on table 5 and table 6 , a comparison of PSNR values can be generated with the AOMDV and DSDV routing protocol.

The decrease and increase in PSNR value can be influenced by the size of the packet loss value (Bondal et al., 2016).

The following is a comparison of the results of the videos that have been compressed based on the largest PSNR values found in tables 5 and table 6 .

\section{Conclusion}

The results of AOMDV routing protocol were obtained, the greater variation in the number of nodes and the distance between nodes has an impact on the higher value of packet loss, the decrease in throughput value, and the value of PSNR. The DSDV routing protocol results is the greater variation in the number of nodes and distance between nodes, which increases the value of packet loss, decreases the drastic throughput compared to the AOMDV routing protocol and decreases the PSNR value and some scenarios do not produce PSNR values at all.

The comparison of PSNR values between the AOMDV and DSDV routing protocols is also influenced by variations in the number of nodes and distances between nodes along with packet loss and throughput parameters. The greater the packet value will decrease the PSNR value generated. The number of node variations and the distance between nodes also affects the good or bad of the PSNR value. The best PSNR value is owned by the DSDV routing protocol with variations in the number of nodes and the distance between the smallest nodes. We also propose that such a study covers further examples of hybrid protocol and using a real-time transmission.

\section{References}

[1] J. He, "Routing Analysis of Protocol AODV in Wireless Mesh Network," no. 41774081, pp. 1-5, 2017.

[2] S. Nefti and M. Sedrati, "PSNR and Jitter Analysis of Routing Protocols for Video Streaming in Sparse MANET Networks, using NS2 and the Evalvid Framework," 2016.

[3] M. J. J. Al-Asfoor, "A Simulation of a Networked Video Monitoring System Using NS2," 2017.

[4] R. R. Sekhar and D. P. Chennareddy, "An Efficient Multipath Routing Protocol with Replication for On-demand Video Streaming in MANETs," 2016.

[5] Y. R. Wani, D. S. Sharma, and S. Chopra, "Video Quality Evaluation of MPEG-4 Using (MOS) Mean Opinion Score in NS-2," 2017. 
[6] W. Zhang, J. He, G. Gao, L. Ren, and X. Shen, "Routing Analysis of Protocol AODV in Wireless Mesh Network," 2017.

[7] S. A. Madani, J. H. Kazmi, and S. Mahlknecht, "Wireless sensor networks: modeling and simulation 1 Wireless sensor networks: modeling and simulation." 2012. https://doi.org/10.5772/9902

[8] E. Setijadi, "Performance Comparative of AODV, AOMDV and DSDV Routing Protocols in MANET Using NS2," pp. 286-289, 2018. https://doi.org/10.1109/isema ntic. 2018.8549794

[9] K. V. D. Bondal, J. F. S. Castellano, L. A. F. Esteban, C. K. V. Teodoro, and A. R. Dela Cruz, "Video packet loss rate prediction over delay-prone packet-based networks," 8th Int. Conf. Humanoid, Nanotechnology, Inf. Technol. Commun. Control. Environ. Manag. HNICEM 2015, no. December, pp. 9-12, 2016. https:// doi.org/10.1109/hnicem.2015.7393257

\section{$7 \quad$ Authors}

Siti Ummi Masruroh is lecturer at informatics department, faculty of science and technology at Informatics Department, Universitas Islam Negeri Syarif Hidayatullah Jakarta, Indonesia. Email: ummi.masruroh@uinjkt.ac.id

Ahmad Nurul Fajar is a lecturer at Information Systems Management Department, BINUS Graduate Program - Master of Information Systems Management, Bina Nusantara University, Jakarta, Indonesia 11480.

Mufid Fajar Alghifari is student at informatics department, faculty of science and technology at Informatics Department, Universitas Islam Negeri Syarif Hidayatullah Jakarta, Indonesia. Email: mufid.ghifari@gmail.com

Luh Kesuma Wardhani is lecturer at informatics department, faculty of science and technology at Informatics Department, Universitas Islam Negeri Syarif Hidayatullah Jakarta, Indonesia. Email: luhkesuma@uinjkt.ac.id

Article submitted 2020-02-12. Resubmitted 2020-08-09. Final acceptance 2020-08-10. Final version published as submitted by the authors. 